\title{
Prevention of congenital RUbella and CONGENital VARICELLA IN EUROPE
}

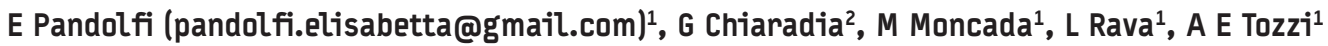 \\ 1. Paediatric Hospital Bambino Gesù, Rome, Italy \\ 2. Catholic University, Hygiene Institute, Rome, Italy
}

Rubella and varicella zoster virus (VZV) infections during pregnancy can cause severe adverse outcomes in the embryo or foetus. Despite the availability of safe and efficacious vaccines, cases of congenital rubella and varicella syndrome still occur in Europe. As of 2004, several countries had high proportions of women of childbearing age that were susceptible to rubella and varicella virus infection. Effective immunisation strategies to enhance prevention should include an active role of different medical specialists in order to include all medical consultations a person may have at different points in their lives as an opportunity to immunise susceptibles. Linkage of data on infectious diseases with those from congenital defects registries may be helpful to monitor the epidemiology of congenital rubella and varicella.

\section{Introduction}

Women have an increased risk of acquiring certain transmissible diseases during pregnancy due to transient immunosuppression [1]. Although many infectious diseases can be prevented by vaccination during childhood, appropriate immunisation of women of childbearing age is crucial in preventing diseases in their offspring that may occur during embryonal/foetal life or early after birth. Because many immunisations, if performed during pregnancy, may theoretically pose a risk for the unborn child, immunisation strategies should be integrated where possible with preconceptional care.

Prevention of congenital rubella syndrome is one of the priorities set by the World Health Organization (WHO) Regional Office for Europe. In 1998, the target of one case of CRS per 100,000 live births by 2010 was approved as a goal of immunisation programmes in the Region $[2,3]$.

This paper tries to draw a picture of the epidemiology of rubella and varicella infections in Europe and the potential for their transmission to pregnant women and presents with possible strategies to enhance prevention of these infections.

\section{Rubella}

\section{Epidemiology}

Reliable data on the incidence of CRS are difficult to obtain for various reasons: because of weakness of the surveillance systems, because rubella in pregnancy can be asymptomatic, because CRS can present with incomplete clinical signs, and because specific symptoms may appear late in the infection.
From 2001 to 2003, a total of 47 cases of CRS were reported from member states of the WHO European Region, decreasing from 21 cases in 2001 to 12 cases in 2003 [4-6]. Moreover, 36\% of these cases were reported from Romania and 32\% from the Russian Federation, whereas the last CRS cases in Finland and Denmark, where coverage for MMR vaccine has been high for many years, was recorded in 1986 [7]. In 2004, 15 member states did not report information on CRS to the WHO, but 14 member states reported 17 cases of CRS [2]. In Italy, where a national campaign for measles and CRS elimination has been reinforced since 2003 [8], the annual incidence rate of CRS has consistently exceeded the WHO goal of one per 100,000 newborns between 1996 and 2002 , with a peak in 2001 of six per 100,000 [9,10]. Recent data suggest that rubella outbreaks still occur in women of childbearing age in Italy. In the period between 2005 and 2008, 30 confirmed cases of rubella have been reported in pregnant women, and four confirmed CRS cases have been diagnosed [11].

The trend of rubella infections in European countries can be obtained from data reported to the WHO by the countries of the WHO European Region, and from data reported to EUVAC.NET, a European surveillance network for vaccine preventable diseases that includes 18 European Union countries [12]. Data reported to the two systems from 2000 to 2007 are shown in figure 1 [12]. Data from both surveillance systems indicate a sharp decrease in the number of cases after 2003, and a stable number of cases since 2005.

According to the European Centre for Disease Prevention and Control (ECDC), 1,498 rubella cases were reported from 22 countries in 2005 . The highest incidences were reported by Lithuania (3.44 per 100,000$)$ and the Netherlands $(2.23$ per $100,000)$. The overall incidence in the 22 countries was 0.51 per 100,000 [13]. As a result of suboptimal immunisation coverage for rubella, several outbreaks have been recorded in Europe in the last decade. In the period from 2002 to 2003 , a large rubella outbreak was observed in Romania with 115,000 reported cases mainly in school-aged children with no difference in incidence by sex [14]. A large rubella and CRS outbreak was described in 1993 in Greece, with 25 serologically confirmed cases (24.6 per 100,000 live births); the incidence decreased after this, but another epidemic occurred in 1999, mainly in young adults, with four cases of CRS (4.0 cases per 100,000 live births). The CRS incidence in Greece remained low until $2003[15,16]$. Rates of CRS as high as 350 
per 100,000 live births have been described during outbreaks in the Russian Federation between 2002 and 2004 [1]. In Turkey, there was no surveillance system for rubella and CRS until 2005. In 2005, with a new surveillance system, 2,245 rubella cases were reported - an incidence rate of 3.1 per 100,000 inhabitants - and only one case of CRS in the same year [17]. In the United Kingdom (UK), measles-mumps-rubella (MMR) vaccination controlled rubella in children and women of childbearing age, but an epidemic in 2005 showed that individuals born between 1982 and 1986 who had never been previously exposed to natural infection were still susceptible [18-21].

Seroprevalence data from the European Sero-Epidemiology Network (ESEN) study performed between 1996 and 2003 showed that women in several countries included in the study were not sufficiently protected against rubella infection (Figure 2) [22].

In Finland and the Netherlands on the other hand, a low rate $(<5 \%)$ of susceptibles in childhood and adolescents of both sexes was observed in the period from 1996 to 2004 [7,23]. In Italy,

\section{F I G U R E 1}

Reported number of rubella cases to WHO and EUVAC.NET, $2000-2007(n=2,073,229)^{*}$

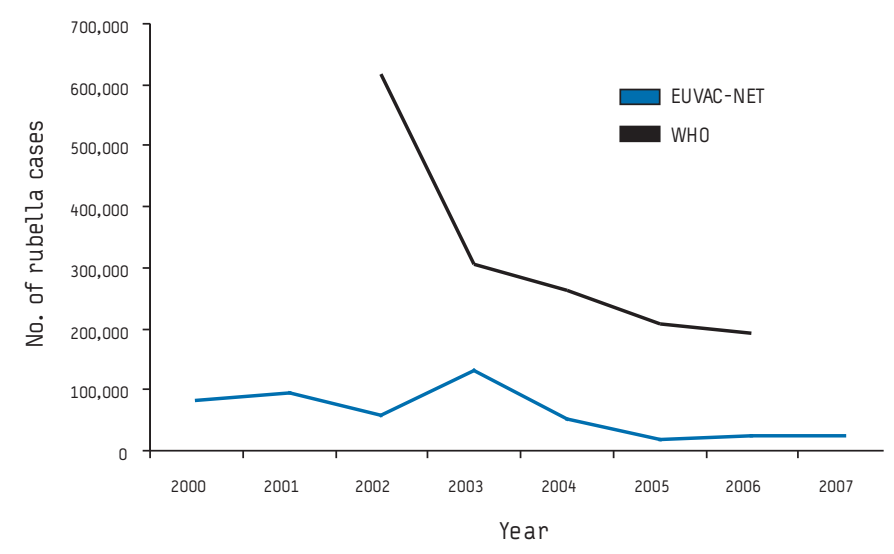

* source: $[11,23,24]$

\section{F I G U R E 2}

Proportion of women susceptible to rubella, by age group, $1996-2003^{\star}$

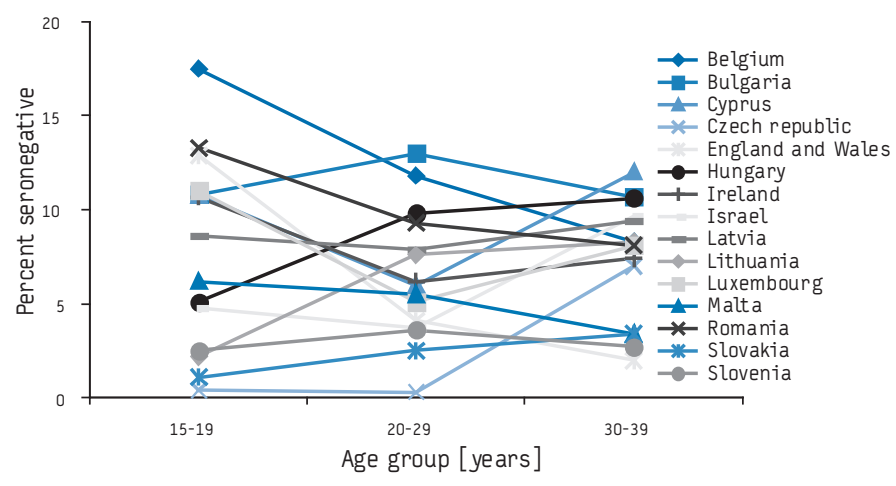

* source: $[16]$ seroprevalence data from 2004 showed $11 \%$ of susceptible women in the age group of $15-19$ year-olds, and $8 \%$ in the $20-39$ yearolds [11].

\section{Prevention strategies}

In order to meet the WHO target of one case of CRS per 100,000 live births by 2010 and to achieve elimination of measles, a measles and CRS elimination strategy was launched in 2002 [3]. The success of current policies in countries using the rubella vaccine has been considerable. The use of rubella combined vaccine has markedly increased since 2002 in the European Region. However, eastern European countries have only recently introduced the MMR vaccine, and some countries in western Europe, where the vaccine has been used for a longer time, have historically had inadequate coverage rates (Table) [18]. In addition, several countries have only recently moved from a one-dose strategy to a two-dose strategy for rubella-containing vaccine $[3,12,24]$.

Use of rubella-containing vaccine in WHO/Europe member states has increased from $38(75 \%)$ of 51 countries in 2001 to $48(92 \%)$ of 52 countries in 2007; Currently 47 member states use at least one dose of a combined MMR vaccine in their childhood immunisation programmes $[3,24]$. Given that most countries in Europe have chosen to use combined measles-rubella (MR) or MMR vaccines, rubella elimination is feasible within a framework of measles elimination [12].

Rubella-susceptible women immigrating from outside Europe have been identified as an important target group for immunisation. Programmes to immunise newly arrived women and adolescent girls are necessary, because they may have contracted rubella in a high-incidence country that does not have a rubella immunisation programme and give birth to an infant with CRS. International vaccination centres should make an effort to immunise immigrant people visiting friends and relatives outside Europe. Several supplementary immunisation activities targeting measles- and/ or rubella-susceptible individuals have been conducted in several countries since 2001, including Albania, Cyprus, Italy, Kazakhstan, Kyrgyzstan, Moldova, Montenegro, Serbia, Tajikistan and Turkey [24].

Overall, about $70 \%$ of member states had national immunisation plans in 2004, 60\% had measles elimination plans, but less than $50 \%$ had rubella elimination plans and/or plans for CRS prevention [24].

\section{Varicella}

\section{Epidemiology}

The epidemiology of congenital varicella (CV) can be derived only indirectly from ad hoc studies because no European country has a specific surveillance system in place. Moreover, in some European countries Denmark, Iceland, Ireland, Northern Ireland, Norway, Sweden, Switzerland and Turkey, varicella disease is not under surveillance. Others Belgium, England and Wales, France, Germany, the Netherlands and Portugal have data derived from sentinel surveillance systems $[25,26]$.

More than $90 \%$ of European children contract chickenpox in the first 10-12 years of life [27-30]. In 2002-2003 the estimated incidence in the UK was 262 varicella cases per 100,000 nulliparous women aged 15-44 years, with 10 of these cases occurring during pregnancy and resulting in nearly 0.06 cases of congenital varicella and 0.16 cases of neonatal varicella per 
100,000 live births $[25,28]$. In 2002-2003, the majority of varicella cases in European countries were reported from Spain $(28 \%)$, Poland (18\%) and Italy (14\%) [26,31].

In Italy, only $78 \%$ of 15 year-olds had antibodies to VZV between 1996 and 2003, and $18 \%$ of female teenagers were seronegative for VZV $[25,30,31]$. In the same period, nearly $90 \%$ of people in the UK had serological evidence of infection by the age of 20 years $[28,30]$. In Spain, the prevalence of VZV antibodies in the period from 1996 to 2003 was $94 \%$ in pregnant women aged $15-24$ years, $95 \%$ in those aged $25-29$ years and $>95 \%$ in those aged 30-49 years [30-32]. The seroprevalence was $97.8 \%$ at the age of 10 years in Switzerland, and more than $90 \%$ at the age of nine years in Belgium, in the season 2000-1 [26,31].

In most European countries less than $5 \%$ of women of childbearing age (between 15 and 39 years-old) were seronegative for VZV in the period from 1996 to 2003 , except in Italy (12.6\%), Israel (7.6\%), and Ireland (5.4\%). In Finland, VZV seroprevalence was $96.2 \%$ in 2000 [31-33].

\section{Prevention strategies}

Safe and effective vaccines against varicella have been available in Europe for the last ten years. The increase in the age at onset, the burden of complications and the direct and indirect costs have prompted several countries to consider universal immunisation programmes for varicella.

Germany is the only country in Europe that has a routine universal childhood varicella immunisation programme, introduced in 2004, with a single dose administered to children at the age of 11-14 months and a catch-up dose for adolescents aged 9-17 years who have a negative history of chickenpox [34]. In April 2006, the combined MMR-varicella (MMR-V) vaccine was licensed in Europe, but it is as yet not available. However, a two-dose MMR-V schedule is likely to replace the monovalent vaccine at least in Germany $[25,34]$.

In Spain, varicella vaccine is recommended for all healthy susceptible adolescents ( $\leq 13$ years), all children with chronic diseases, organ transplant recipients, seronegative households and health contacts of high-risk children [25]. The community of Madrid adopted universal infant vaccination in October 2006 [25]. Other countries including Cyprus, Italy, Latvia, Slovenia, Switzerland, and the UK recommend immunisation to high risk patients, seronegative healthcare workers, seronegative family members of high-risk patients, and adolescents with no recollection of having had the disease [25].

No specific programmes or initiatives have been endorsed so far by the WHO to promote varicella immunisation or prevention of congenital varicella.

\section{How to enhance prevention strategies}

Integration of preconception components into primary care can better serve women at various levels of risk across their lifespan [35]. Depending on the age group in which prevention strategies should be applied, prevention of CRS and CV require a strong integration of several activities which involve different professional levels.

\section{Children and adolescents}

Universal immunisation programmes targeted to children are already in place for rubella. The WHO Regional Office for Europe developed and implemented a strategic plan for the prevention of measles and congenital rubella infection in the WHO European Region in 2002 [3]. This plan targeted the elimination of measles and the prevention of congenital rubella infection for the year 2010.

\begin{tabular}{|c|c|c|c|c|c|c|c|}
\hline \multirow[t]{2}{*}{ Country } & \multicolumn{2}{|c|}{$\begin{array}{c}\text { Year of introduction } \\
\text { of childhood rubella } \\
\text { vaccination }\end{array}$} & \multirow[t]{2}{*}{$\begin{array}{l}\text { Recommended age for } \\
\text { second dose }\end{array}$} & \multirow[t]{2}{*}{$\begin{array}{l}\text { Average vaccine } \\
\text { coverage among infants } \\
(\%)\end{array}$} & \multirow[t]{2}{*}{$\begin{array}{l}\text { Adolescent female } \\
\text { vaccination (years) }\end{array}$} & \multirow[t]{2}{*}{$\begin{array}{l}\text { Antenatal } \\
\text { screening as of } \\
2003\end{array}$} & \multirow[t]{2}{*}{$\begin{array}{l}\text { Average rubella } \\
\text { incidence } \\
\text { (per 100,000) }\end{array}$} \\
\hline & One dose & Two dose & & & & & \\
\hline Belgium & 1985 & 1994 & 11 & 82 (1999) & $1973-1994$ & Yes & $0.2(2001-2003)$ \\
\hline Bulgaria & 1992 & 2001 & 12 & 93 (1999-2003) & $1988-2001$ & - & 86.8 (1999-2003) \\
\hline Cyprus & - & 1989 & $4-6$ & 86 (1999-2003) & 1974-1989 & Yes & 0.2 (1999-2003) \\
\hline Czech Republic & - & 1986 & 2 & $97(1999,2001,2003)$ & 1982-1997 & - & 11.3 (1999-2003) \\
\hline England and Wales & 1988 & 1996 & $4-5$ & 85 (1999-2003) & 1970-1988 & Yes & 0.1 (1999-2003) \\
\hline Hungary & 1991 & 1999 & 11 & $100(1999,2002,2003)$ & - & - & 0.7 (1999-2003) \\
\hline Ireland & 1988 & 1992 & 4-5 & 76 (1999-2003) & 1971-1988 & Yes & 1.6 (1999-2003) \\
\hline Israel & 1988 & 1995 & $6-7$ & 95 (1999-2003) & 1973-1999 & - & 0.2 (1999-2003) \\
\hline Latvia & 1993 & 2002 & 7 & 97 (1999-2003) & $1993-2002$ & - & 29.0 (1999-2003) \\
\hline Lithuania & - & 1992 & $6-7$ & 97 (1999-2003) & $1992-1996$ & - & 20.2 (1999-2003) \\
\hline Luxembourg & 1986 & 1994 & $5-6$ & - & - & Yes & $0.8(2000-2001)$ \\
\hline Malta & 1989 & 1992 & 12 & 74 (1999-2003) & 1976-1992 & - & 1.0 (1999-2003) \\
\hline Romania & - & - & - & - & - & - & $136.3(1999-2003)$ \\
\hline Slovakia & 1985 & 1992 & 11 & 99 (1999-2003) & 1985-1992 & - & 0.3 (1999-2003) \\
\hline Slovenia & - & 1990 & $6-7$ & 93 (1999-2003) & 1973-1990 & - & 0.5 (1999-2003) \\
\hline Sweden & - & 1982 & 12 & 92 (1999-2002) & $1972-1982$ & - & $<0.1$ (1999-2003) \\
\hline
\end{tabular}

* source: [17] 
Nonetheless, the success in eliminating a transmissible disease depends mostly on the coverage level that is achieved. Measles elimination has already been achieved in some member states through routine immunisation programmes, which maintain high measles vaccine coverage using a two-dose schedule [2,36]. Since most European countries use combined measles vaccines including the rubella component, policies toward measles elimination should result in concurrent elimination of CRS [36]. Strategies for elimination of measles and CRS should be sustained in the entire WHO European Region maintaining coverage levels over 95\% for rubella-containing vaccines. Catch-up programmes must also be maintained to avoid the accumulation of susceptibles in the general population. It should be considered that it is unlikely that universal programmes for varicella immunisation will be implemented in the short term in all countries of the WHO European Region. The recent licensure of MMR-V, however, may favour a link with measles and congenital rubella elimination strategy in the near future. Since patients reliably remember having had varicella, a minimal approach for prevention of varicella in pregnancy may consist of a verbal screening of adolescents to choose those eligible for immunisation. Some countries already actively offer varicella immunisation to high risk children. Although this strategy is directed to a small proportion of the general population, it is essential to monitor its impact. If susceptible individuals accumulate as an effect of targeted immunisation strategy, outbreaks may occur in this group at an older age, when varicella is more likely to be severe [37].

These potential strategies rely on the integration of roles of public health officers with those of family paediatricians and general practitioners [27].

\section{Women of childbearing age}

Information programmes should be in place to disseminate and to promote screening and immunisation against measles, mumps, rubella, and varicella in susceptible women of childbearing age. These programmes may be particularly effective if not limited to women who plan a pregnancy. Every visit of this target population to a gynaecologist or general practitioner may include counselling, screening, and oriented recommendations for immunisation. It is necessary to include rubella virus antibody screening in prenatal care even in countries with well-established vaccination programmes. One needs to keep in mind that people do not reliably recall a past rubella infection and that, in cases where it is not possible to determine the immunisation status or the presence of specific IgG antibodies, a woman must be considered susceptible. Vaccines against rubella and varicella infections should be offered to all women of childbearing age who do not have acceptable evidence of immunity [38,39].

\section{Women during pregnancy}

Screening and diagnosis of rubella and varicella infections during pregnancy pose particular problems. Communication of screening results to pregnant women may result in termination of pregnancy $[38,39]$. Besides the fact that the performance of commercial diagnostic tests is variable, it must be kept in mind that as the true incidence of a certain disease becomes low, the positive predictive value of diagnostic tests for confirming recent infection declines as well. This is particularly relevant for rubella infection in countries in which elimination has almost been achieved $[22,39]$. A woman identified as susceptible to rubella or varicella should be followed until the end of pregnancy to ensure that she will be immunised soon after delivery [22,39].

\section{Women after delivery or abortion}

Since delivery or abortion take place in medical facilities, this setting is particularly appropriate for administering due immunisations provided that information on previous screening is communicated. Cost-effectiveness analysis of antenatal varicella screening with post-partum vaccination of susceptibles suggests that the screening and vaccination strategies are more costeffective in preventing cases in women than with the strategy to treat cases as they arise [27]. In case information on screening is not available, diagnostic tests may be offered to women with unknown susceptibility to rubella and varicella [27,39].

Women who have already had children are very likely to consult a family paediatrician before another pregnancy. For this reason, mothers can be verbally screened and provided with specific recommendations during paediatric consultation. This strategy could be added to that based on visits to general practitioners.

\section{Surveillance and seroprevalence}

The WHO Regional Office for Europe launched a strategic plan in 2005 to eliminate congenital rubella [3]. A European measles and rubella laboratory network was established in 2002 [3]. At present, 47 member states (90\%) have a national measles/rubella laboratory, which is linked to one of three WHO European Region reference laboratories appointed in 2003 or to the specialised laboratory located in the European Region. The network has implemented standardised diagnostic methods and reagents, and a quality assessment programme, including proficiency testing and monthly online reporting of laboratory performance indicators; completeness of reporting from national laboratories was $70 \%$ in 2004 [3]. Seroprevalence studies should be encouraged periodically to precisely identify population groups that may be targeted for special prevention strategies. While surveillance of rubella is in place in all WHO European countries and many of them also have a system for varicella, much effort should still be devoted to surveillance of congenital rubella and congenital varicella $[4,25]$. Moreover, member states use different methods to collect measles and rubella data, including aggregate, case-based, and sentinel physician reporting, which require standardisation [2]. This activity could benefit from cooperation between public health professionals working in surveillance of transmissible infections and congenital defects registries regarding the sharing of data and the use of similar case definitions. Under-notification is a well recognised limitation of nationwide mandatory notification systems. It is therefore necessary to enhance the quality of surveillance systems and sero-epidemiology, particularly in countries in which the disease is under control $[1,20,25]$.

\section{Integration with other prevention strategies}

Women of childbearing age should receive preconceptional counselling whenever they interact with medical facilities. General and hospital practitioners, gynaecologists and obstetricians, and possibly professionals in other specialties, should offer information for the prevention of adverse events in pregnancy advocating appropriate lifestyle habits, food and vitamin intake, and prudent use of drugs. Prevention of transmissible disease through immunisation, not only against rubella and varicella, should be one of the most important parts of preconceptional counselling.

\section{Conclusions}

Preconceptional screening and immunisation of pregnant women are not yet adequate in Europe. European countries should endorse common strategies to improve as much as possible the impact of recommendations for the prevention of rubella and varicella 
in pregnancy. This is possible only through the coordination and integration of several activities and different actors who should share the final goal of preventing cases of these diseases.

\section{References}

1. Robinson JL, Lee BE, Preiksaitis JK, Plitt S, Tipples GA. Prevention of Congenital Rubella Syndrome-What Makes Sense in 2006? Epidemiol Rev. 2006;28:81-7.

2. World Health Organization. WHO vaccine-preventable diseases monitoring system: 2005 global summary. Geneva, Switzerland: World Health Organization; 2005.

3. Eliminating measles and rubella and preventing congenital rubella infection: WHO European Region strategic plan 2005-2010. WHO Library Cataloguing in Publication Data. Copenhagen: World Health Organization Regional Office for Europe; 2005, updated reprint 2006. ISBN 92-890-1382-6. Available from: http:// www.euro.who.int/Document/E87772.pdf

4. Spika JS, Hanon FX, Wassilak S, Pebody RG, Emiroglu N. Preventing congenital rubella infection in the European Region of WHO: 2010 target. Euro Surveill. 2004;9(4):pii=455. Available from: http://www.eurosurveillance.org/ViewArticle. aspx?ArticleId $=455$

5. Public Health Authority of the Slovak Republic. Action Plan for maintaining the Elimination of Measles and Congenital Rubella Syndrome and for Elimination of Rubella in the Slovak Republic. 2008. Available from: http://www.euvac. net/graphics/euvac/pdf/plan_slovakia_eng.pdf

6. Centers for Disease Control and Prevention (CDC). Progress Toward Elimination of Measles and Prevention of Congenital Rubella Infection --- European Region, 1990-2004. MMWR Morb Mortal Wkly Rep. 2005 Feb 25;54(7):175-8.

7. Davidkin I, Peltola H, Leinikki P. Epidemiology of rubella in Finland. Euro Surveill. 2004:9(4):pii=459. Available from: http://www.eurosurveillance.org/ ViewArticle.aspx?ArticleId $=459$

8. Bonanni P, Bechini A, Boccalini S, Peruzzi M, Tiscione E, Boncompagni G, et al. Progress in Italy in control and elimination of measles and congenital rubella. Vaccine. 2007;25(16):3105-10.

9. Buffolano W, Lorenzo E, Lodato S, Parlato A, Pizzuti R. Surveillance of congenital rubella: the Campania “Perinatal Infections" Registry experience. Onlus Rete Punti Nascita Regione Campania, Servizi Epidemiologia e Prevenzione ASL Regione Campania (SEP). BEN-Notiziario ISS. 2003;16(5)

10. Giambi C, Rota MC, Bella A, Filia A, Gabutti G, Guido M, et al. Rubella epidemiology in Italy in years 1998-2004. Ann Ig. 2007;19(2):93-102.

11. Giambi C, Filia A, Ciofi degli Atti ML, Rota MC and Salmaso S. Allarme rosolia: promuovere gli interventi per vaccinare le donne suscettibili in età fertile. [ Increase in rubella: to promote interventions the interventions to vaccinate susceptible women of childbearing age]. Ben Not Ist Super Sanità. 2008;21(5):i-ii. [In Italian]. Available from: http://www.epicentro.iss. it/ben/2008/maggio/1.asp

12. Rubella trends. EUVAC.NET; 2008 May 13. Available from: http://www.euvac.net/ graphics/euvac/trends_rubella.html

13. Rubella - Epidemiological situation. European Centre for Disease Prevention and Control (ECDC). Available from: http://ecdc.europa.eu/en/Health_Topics/ Rubella/aer_07.aspx. [Accessed on 23/06/2008]

14. Rafila A, Marin M, Pistol A, Nicolaiciuc D, Lupulescu E, Uzicanin A, et al. A large rubella outbreak, Romania - 2003. Euro Surveill. 2004;9(4):pii=457. Available from: http://www.eurosurveillance.org/ViewArticle. aspx?ArticleId $=457$

15. Panagiotopoulos T, Georgakopoulou T. Epidemiology of rubella and congenital rubella syndrome in Greece, 1994-2003. Euro Surveill. 2004;9(4):pii=461. Available from: http://www.eurosurveillance.org/ViewArticle. aspx?ArticleId $=461$

16. Gioula G, Diza-Mataftsi E, Alexiou-Daniel S, Kyriazopoulou-Dalaina V. Seroepidemiology of rubella in northern Greece. Eur J Clin Microbiol Infect Dis. 2004;23(8):631-3.

17. Aksakal FN, Maral I, Cirak MY, Aygun R.Rubella Seroprevalence among women of childbearing age residing in a Rural Region: Is there a need for Rubella Vaccination in Turkey? Jpn J Infect Dis. 2007;60(4):157-60.

18. Nardone A, Tischer A, Andrews N, Backhouse J, Theeten H, Gatcheva N, et al. Comparison of rubella seroepidemiology in 17 countries: progress towards international disease control targets. Bull World Health Organ. 2008;86(2):11825.

19. Hawker JI, Olowokure B, Wood AL, Wilson RC, Johnson R. Widening inequalities in MMR vaccine uptake rates among ethnic groups in an urban area of the UK during a period of vaccine controversy (1994-2000). Vaccine. 2007;25(43):75169 .
20. Crowcroft N, Pebody RG. Prevention of congenital rubella infection: a challenge for every country in Europe. Euro Surveill. 2004;9(4):pii=454. Available from: http://www.eurosurveillance.org/ViewArticle. aspx?ArticleId $=454$

21. Gupta RK, Best J, MacMahon E. Mumps and the UK epidemic 2005. BMJ. 2005;330(7500):1132-5.

22. Tischer A, Andrews N, Kafatos G, Nardone A, Berbers G, Davidkin I, et al. Standardization of measles, mumps and rubella assays to enable comparisons of seroprevalence data across 21 European countries and Australia. Epidemiol Infect. 2007;135(5):787-97.

23. Pebody RG, Edmunds WJ, Conyn-van Spaendonck M, Olin P, Berbers G, Rebiere I, et al. The seroepidemiology of rubella in western Europe. Epidemiol Infect. 2000;125(2):347-57.

24. Best JM, Castillo-Solorzano C, Spika JS, Icenogle J, Glasser JW, Gay NJ, et al. Reducing the Global Burden of Congenital Rubella Syndrome: Report of the World Health Organization Steering Committee on Research Related to Measles and Rubella Vaccines and Vaccination, June 2004. J Infect Dis. 2005;192(11):1890-7.

25. Sengupta N, Booy R, Schmitt HJ, Peltola H, Van-Damme P, Schumacher RF, et al. Varicella vaccination in Europe: are we ready for a universal childhood programme? Eur J Pediatr. 2008;167(1):47-55.

26. Thiry N, Beutels P, Shkedy Z, Vranckx R, Vandermeulen C, Wielen MV, et al. The seroepidemiology of primary varicella-zoster virus infection in Flanders (Belgium). Eur J Pediatr. 2002;161(11):588-93.

27. Pinot de Moira A, Edmunds WJ, Breuer J. The cost-effectiveness of antenatal varicella screening with post-partum vaccination of susceptible. Vaccine. 2006 Feb 27;24(9):1298-307.

28. McKendrick MW, Lau J, Alston S, Bremner J. VZV infection in pregnancy: A retrospective review over 5 years in Sheffield and discussion on the potential utilisation of varicella vaccine in prevention. J Infect. 2007;55(1):64-7.

29. Banz K, Wagenpfeil S, Neiss A, Hammerschmidt T, Wutzler P. The burden of varicella in Germany. Potential risks and economic impact. Eur J Health Econ. 2004;5(1):46-53.

30. Nardone A, de Ory F, Carton M, Cohen D, van Damme P, Davidkin I, et al. The comparative sero-epidemiology of varicella zoster virus in 11 countries in the European region. Vaccine. 2007;25(45):7866-72.

31. Pinot de Moira A, Nardone A. Varicella zoster virus vaccination policies and surveillance strategies in Europe. Euro Surveill. 2005;10(1):pii=511. Available from: http://www.eurosurveillance.org/ViewArticle.aspx?ArticleId=511

32. Plans P, Costa J, Espuñes J, Plasència A, Salleras A. Prevalence of varicellazoster antibodies in pregnant women in Catalonia (Spain). Rationale for varicella vaccination of women of childbearing age. BJOG. 2007;114(9):1122-7.

33. Alanen A, Kahala K, Vahlberg T, Koskela P, Vainionpää R. Seroprevalence, incidence of prenatal infections and reliability of maternal history of varicella zoster virus, cytomegalovirus, herpes simplex virus and parvovirus B19 infection in South-Western Finland. BJOG. 2005;112(1):50-6.

34. Rasch G, Hellenbrand W. Germany adds varicella vaccine to the national vaccination program. Euro Surveill. 2004;8(31):pii=2511. Available from: http:// www.eurosurveillance.org/ViewArticle.aspx?ArticleId $=2511$

35. Johnson K, Posner SF, Biermann J, Cordero JF, Atrash HK, Parker CS, et al Recommendations to Improve Preconception Health and Health Care - United States: a report of the CDC/ATSDR Preconception Care Work Group and the Select Panel on Preconception Care. MMWR Recomm Rep. 2006;55(RR-6):1-23.

36. WHO Regional Committee for Europe. Report of the fifthy-fith session. Bucharest, Romania, 12-15 September 2005. Copenhagen: WHO Regional Office for Europe; 2005. Report No. EUR/RC55/REC/1.

37. Salmaso S, Tomba GS, Mandolini D, Esposito N. Assessment of the potential impact in Italy of extensive varicella vaccination programs based on a mathematical model. Epidemiol Prev. 2003;27(3):154-60.

38. Centers for Disease Control and Prevention (CDC). Revised ACIP Recommendations for Avoiding Pregnancy after receiving a Rubella-containing vaccine. MMWR Morb Mortal Wkly Rep. 2001;50(49):1117.

39. Marin M, Güris D, Chaves SS, Schmid S, Seward JF, Advisory Committee on Immunization Practices, et al. Prevention of Varicella: Recommendations of the Advisory Committee on Immunization Practices (ACIP). MMWR Recomm Rep. 2007;56(RR-4):1-40.

This article was published on 5 March 2009. Citation style for this article: Pandolfi E, Chiaradia G, Moncada M, Rava L, Tozzi AE.
Prevention of congenital rubella and congenital varicella in Europe. Euro Surveill. 2009;14(9):pii=19133. Available online: http://www.eurosurveillance.org/ViewArticle. aspx?ArticleId $=19133$ 